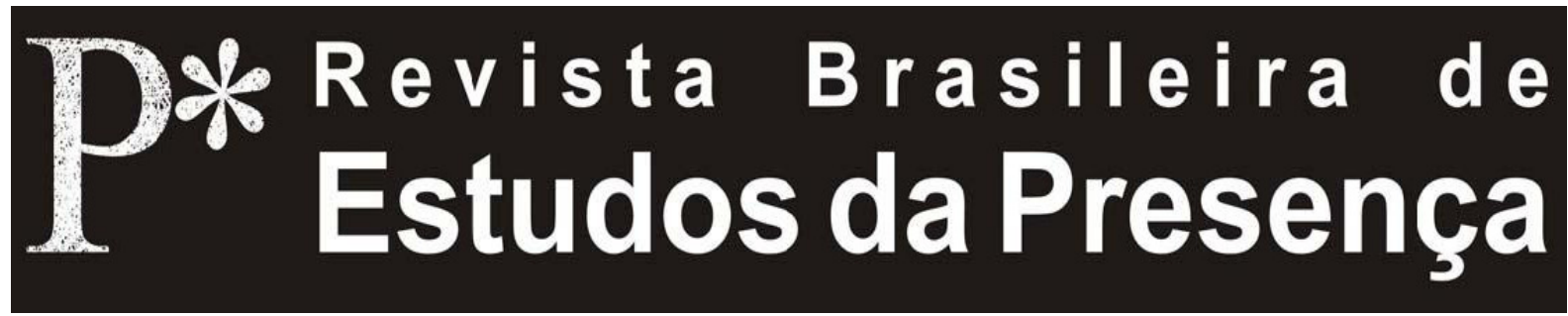

DOI - http://dx.doi.org/10.1590/2237-266039226

ISSN 2237-2660

\title{
La Actuación en el Teatro Posdramático Argentino
}

\author{
Karina Mauro \\ Universidad de Buenos Aires - UBA, Buenos Aires, Argentina
}

RESUMEN - La Actuación en el Teatro Posdramático Argentino - Se abordarán las características que adquiere la actuación porteńa a partir de la inclusión de elementos del Teatro Posdramático durante la década del 1990. Para ello, se analizará la apropiación de dicho universo técnico/estético por el campo teatral porteño y las transformaciones que suscitó tanto en el desempeño actoral como en la formación para la actuación. Estos elementos, basados en la presencia física del actor e inicialmente utilizados en las propuestas transgresoras de los 80, pasan a formar parte del repertorio disponible para el desarrollo de poéticas de dirección y de dramaturgia durante la década siguiente, conformando la expresión porteña del fenómeno Posdramático.

Palabras-clave: Actuación. Teatro. Posdramático. Presencia. Dramaturgia.

ABSTRACT - Acting in Argentine Postdramatic Theatre - This paper addresses the influences of postdramatic theatre in Buenos Aires from the 1990s. Therefore, the appropriation of such technical/aesthetic universe by the theatre of the city and the transformations it provoked in acting and actor's training will be analysed. These elements, based on the physical presence of the actor and initially used in the transgressive proposals of the 1980s, became part of the repertoire available for the development of a poetics of direction and dramaturgy in the following decade, shaping the Buenos Aires expression of the postdramatic phenomenon.

Keywords: Performance. Theatre. Posdramatic. Presence. Dramaturgy.

RÉSUMÉ - Les Acteurs dans le Théâtre Postdramatique Argentin - L'article portera un regard sur les transformations subies par le jeu d'acteur à Buenos Aires lors de l'irruption d'éléments du théâtre postdramatique au cours des années 1990. Il s'agira d'analyser l'appropriation de cet univers technique/esthétique par le champ théâtral porteño et les changements suscitées aussi bien dans le jeu des acteurs que dans leur formation. Ces éléments, fondés sur la présence physique de l'acteur et initialement utilisés dans les propositions transgressives des années 1980, deviennent partie intégrante du répertoire, participant au développement de poétiques de mise en scène et de dramaturgie durant la décennie suivante et confortant ainsi l'expression porteña du phénomène postdramatique. Mots-clés: Acteurs. Théâtre. Postdramatique. Présence. Dramaturgie. 
El presente artículo se propone examinar la productividad de la noción de Teatro Posdramático para analizar ciertas particularidades del campo teatral ${ }^{1}$ porteño de las últimas dos décadas, principalmente en lo referente a la Actuación y a su relación con otros agentes del hecho teatral.

El concepto de Teatro Posdramático fue propuesto por el teórico alemán Hans-Thies Lehmann en el año 1999 en su libro homónimo. Con el mismo, Lehmann buscaba caracterizar las experiencias escénicas realizadas a partir de 1970 en los campos teatrales de Europa y los Estados Unidos. En el último quinquenio, dicho concepto se ha difundido en Sudamérica, siendo adoptado con singular avidez por los teóricos locales.

No obstante, consideramos que es necesario revisar algunos aspectos medulares del concepto de posdrama, antes de establecer un diálogo entre sus postulados y las condiciones del hecho escénico de cada uno de nuestros países, que ya presentan entre sí diferencias sustanciales, ni qué decir respecto de los países centrales a partir de los cuáles el término fue concebido.

La noción de posdrama encierra dos conceptos básicos, a los que presupone. Uno de ellos es explícito, y tiene que ver con una concepción estética e histórica particular del teatro, que es la del drama, caracterizado por Peter Szondi en su célebre Teoría del Drama Moderno. El otro concepto, que se halla velado en la noción de posdrama, supone una concepción determinada de la historia, asociada al término posmodernidad, acuñado por Jean-François Lyotard en $L a$ condición posmoderna (1979).

No es nuestro interés reproducir aquí las implicancias del debate acerca de si nos hallamos en la Posmodernidad o a un estadio postrero de la Modernidad, denominado Modernidad tardía. Pero sí nos interesa resaltar que una utilización del término de Lehmann que no contemple su estrecha conexión ideológica con cierta concepción de la historia, es una lectura, si no irresponsable, por lo menos descuidada de su propuesta teórica. Esto puede inducir a errores acerca de los fenómenos teatrales a analizar, en este caso, los de nuestros países sudamericanos, cuya condición periférica (luego de las profundas crisis socioeconómicas provocadas por el neoliberalismo y sorteadas mediante la renuncia parcial a sus postulados más nocivos), no implica hoy en día necesariamente un perjuicio. 
El lector podría preguntarse entonces si a estas alturas es pertinente o útil plantear la existencia de un Teatro Posdramático en nuestras sociedades, y más específicamente en el campo teatral porteño, tema que nos ocupa en este artículo. La respuesta es que sí. Como todo concepto teórico, el de Teatro Posdramático será productivo siempre y cuando no se lo aplique de forma mecánica e irreflexiva, sino estableciendo un diálogo entre el mismo y las circunstancias socioculturales y escénicas de los países de Sudamérica. En definitiva, es pertinente hablar de Teatro Posdramático aquí, siempre y cuando se considere que es la noción teórica la que debe adecuarse a las manifestaciones escénicas locales, contribuyendo a su esclarecimiento, y no a la inversa.

Realizadas estas salvedades, el presente artículo parte de la hipótesis de que no es posible hablar de Teatro Posdramático en el campo teatral porteño antes de 1990. Consideramos que para argumentar esta afirmación es necesario analizar el rol desempeñado por la Actuación, tanto en las manifestaciones locales del Teatro Posdramático, como en otras formas presentes en el campo teatral porteńo en el período inmediatamente anterior. Con esto, no sólo nos proponemos explorar la existencia del fenómeno posdramático en nuestro medio, sino también señalar la relevancia de la Actuación como elemento dinamizador del campo teatral porteño en su conjunto, con el objeto, en definitiva, de postularla como legítimo objeto de reflexión teórica en los estudios teatrales y culturales.

\section{Drama / Posdrama}

Según Peter Szondi (1994), la elevación del drama como estética canónica fue el resultado de un largo y trabajoso proceso, que coincide con el surgimiento y afianzamiento de la Modernidad y, por consiguiente, con el ascenso social y político de la burguesía. Curiosamente, la consolidación del drama se produce en el mismo momento en el que comienza a ser socavado. En efecto, y reproduciendo el devenir de la hegemonía burguesa, clase que lo proclama como estética teatral privilegiada, el drama no termina de constituirse, cuando ya está siendo cuestionado.

Dichos cuestionamientos vienen dados por aquellos aspectos de la sociedad o de la subjetividad que el drama, considerado en sentido estricto, no podía contener en su seno, tales como la emancipación de la clase obrera, la incomunicación, lo irracional o el pasado que 
interfiere en el presente, y que dificultan la resolución dialéctica de los conflictos (Szondi, 1994).

Con el correr del siglo XX, el drama en tanto teatro de la burguesía para la burguesía que reconfirma mediante el mismo su lugar en la sociedad, será discutido por un teatro que una parte esclarecida de la burguesía, denominada vanguardia política o estética, le dirige a otras clases sociales (tal es el caso del teatro brechtiano) o a todo aquel que logre tolerar la supuesta subversión de los modos de percepción estética habituales (cuyo ejemplo extremo es la elaboración artaudiana). Propuestas portadoras, explícita o implícitamente, de una concepción didáctica y tutelar del teatro, postura magistralmente criticada por Jacques Rancière en El espectador emancipado (2010).

Así, las propuestas superadoras del drama partieron de la denuncia de sus limitaciones y promovieron la ampliación de sus posibilidades de representación, en pos de algún tipo de progreso en la escena, pero fundamentalmente, en lo extrateatral. Es en este punto donde residiría la novedad del fenómeno teatral posdramático. El Teatro Posdramático abandona las pretensiones políticas, racionales y éticas propias de la Modernidad, y que se hallaban presentes tanto en el drama como en las estéticas que salieron a cuestionarlo en sus mismos términos.

Fieles exponentes de su contexto histórico (sea que lo identifiquemos como Posmodernidad o como Modernidad tardía), las manifestaciones teatrales posteriores a 1970 hacen gala de la yuxtaposición de elementos heterogéneos y el desentendimiento por arribar a un relato unificador. Así, Oscar Cornago manifiesta que:

A diferencia de lo que ocurría en las vanguardias, este teatro ya no tiene como estadio de llegada el cuestionamiento de un modelo de representación unitario y con ello la denuncia de los límites del sentido lógico, de la verdad o las abstracciones racionalistas, sino que este estadio se adopta ya como punto de partida previo, es un estado de cosas que se asume desde el comienzo (Cornago, 2005, p. 126).

Para el autor español, el Teatro Posdramático es propio de

[...] una Modernidad que ya no busca la reconstrucción dialéctica y unitaria propuesta por la escena hegeliana (el teatro de las ideas), sino que se construye en defensa de una diferencia que no sea neutralizada por un movimiento de síntesis (Cornago, 2005, p. 138).

En definitiva, aquello de lo que la escena posdramática es el resultado o el fiel testimonio, es de la crisis de la representación y, en términos teatrales, del abandono de la mimesis aristotélica. 
Para Aristóteles la mimesis es una praxis llevada a cabo por el poeta, en la que la garantía de orden y belleza está dada por el mito, es decir, por la correcta composición de la trama o de la acción narrada, a la que los demás componentes del hecho teatral deben subordinarse. Se trata, entonces, de una actividad de disposición del lenguaje, seleccionando y combinando elementos heterogéneos en pos de la conformación de una totalidad de sentido que legitimará el desempeño de los actores, escenógrafos, vestuaristas, etc. Así, postula como meros ejemplos de buena composición, a las célebres unidades de tiempo, acción y lugar, que las posteriores lecturas de la obra de Aristóteles se encargarían de elevar como canon.

De este modo, será a través de la hegemonía de la trama que la propuesta aristotélica establecerá la preponderancia de la dimensión transitiva de la representación.

Siguiendo a Louis Marin, Roger Chartier (1996) distingue dos dimensiones de la noción de representación: la transitiva y la reflexiva. La representación de carácter transitivo constituye la sustitución de algo ausente por un objeto, imagen o elemento nuevo, por lo que éste se vuelve transparente en favor de aquello que refiere. El carácter reflexivo, en cambio, consiste en la autorrepresentación del nuevo elemento y la mostración de su presencia, mediante la cual el referente y su signo forman cuerpo, son la misma cosa. Si bien Chartier afirma que toda enunciación se presenta a sí misma representando algo, por lo que ambas dimensiones coexisten, reconoce que aquello que denomina como "las modalidades de la 'preparación' para comprender los principios de la representación” (Chartier, 1996, p. 90) pueden provocar que se priorice la función sustitutiva en detrimento de la reflexiva.

En efecto, la interpretación dominante de la mimesis aristotélica en el arte teatral occidental ha priorizado la dimensión transitiva de la representación, concebida como la referencia a una idea o sentido (la trama) que se halla ausente de la situación escénica y que es sustituida en y a través de ésta. La construcción de la trama implicará entonces un ejercicio de poder, mediante el cual el autor de la misma se convierte en el dueño. La disposición que el arte teatral recibe del imperio de la trama, constituye lo que Derrida (1967) denomina una escena teológica, en tanto responde a un logos primero que no pertenece al lugar teatral, pero que lo gobierna a distancia: 
La escena es teológica en tanto que su estructura comporta, siguiendo a toda la tradición, los elementos siguientes: un autor-creador que, ausente y desde lejos, armado con un texto, vigila, reúne y dirige el tiempo o el sentido de la representación, dejando que ésta lo represente en lo que se llama el contenido de sus pensamientos, de sus intenciones y de sus ideas (Derrida, 1967, p. 322).

Ahora bien, de todas las diversas lecturas e interpretaciones que la obra aristotélica ha tenido a lo largo de la historia, el Drama Moderno constituiría el punto máximo, dado que permite la eliminación de los últimos vestigios del "yo épico" o del sujeto de la enunciación en el arte teatral (Szondi, 1994). Esto significa que la construcción de la trama ha logrado una composición y un sentido unitario tan perfecto, que la acción parece desarrollarse por sí misma, ante la presencia de los espectadores.

Esto sucede porque el dramaturgo ha hecho una total cesión de la palabra en favor de los personajes, cuyos diálogos conformarán la totalidad del enunciado teatral, que pasa a constituirse así como una dialéctica cerrada en la que los conflictos se resuelven sin intervención externa. El triunfo del sentido unitario de la trama y de la representación transitiva en el drama es tal, que no sólo la posición del dramaturgo se ve reforzada, sino que además promueve el surgimiento de una nueva figura, que será su representante en la puesta en escena: el director.

Pero hay aún más. El drama, en tanto dialéctica cerrada, afianza uno de los pilares de la concepción que la burguesía tiene del ámbito público, que es la elevación del diálogo como escenario privilegiado para la interacción humana, lo cual presupone una interioridad de los sujetos que se expresa mediante la palabra. Así, comienzan a surgir manifestaciones prácticas y estéticas que serán funcionales a estos postulados, como son el desarrollo del realismo como poética más cara al drama, la elaboración de la metodología de actuación naturalista (cuya consigna es que todo signo exterior emitido por el actor debe ser la expresión de una vivencia interna) y la noción de subtexto, en tanto garantía de la correcta representación de la trama construida por el dramaturgo y refrendada por el director.

¿Qué sucede en el Teatro Posdramático? Se trata, según refiere el propio Lehmann, de un teatro antiaristotélico, en el que la dinámica escénica es colocada por sobre la dinámica dramática. Esto significa básicamente, que el hecho escénico no parte desde, ni busca arribar $a$, un sentido unificado que pueda identificarse con un referente externo previo. 
Pero, ¿qué significa esto en profundidad? ¿En qué radica el desafío de superar la dinámica dramática? Consideramos que el Teatro Posdramático busca, en definitiva, conseguir que el teatro logre realizar finalmente el movimiento que las artes plásticas llevaron adelante a principios del siglo XX, cuando empujadas por la crisis de la representación con la que las enfrentó la invención de la fotografía, debieron hurgar en sus principios lingüísticos y matéricos esenciales.

Así, confrontando el mecanismo de la representación teatral con algún tipo de límite (Cornago, 2005), el Teatro Posdramático busca la reivindicación de la materialidad y del lenguaje propiamente escénicos, por sobre la producción de sentido, es decir, la reivindicación de la dimensión reflexiva del hecho teatral, subordinada durante siglos a la dimensión transitiva compuesta por la trama.

Se trata, finalmente, de arribar a la mostración de una realidad que no puede ser representada (Cornago, 2005) o, más específicamente, de un resto de la realidad (lo real) que se resiste a ser simbolizado por el discurso, siendo sólo perceptible, según Lyotard (1970), como "figura", es decir, en su opacidad. Para el filósofo francés, si anteriormente la representación y el sentido sustituyeron al referente a partir de un desplazamiento, en la Modernidad de final de siglo no hay nada que reemplazar. Si ya no hay relación de "verdad" e "ilusión" o de causa y efecto, significado y significante coexisten independientemente como potencias e intensidades, dando lugar a lo que denomina como un "teatro energético" (Lyotard, 1981).

¿Cómo arriba el Teatro Posdramático a esta reivindicación de lo estrictamente escénico, es decir, de la dimensión reflexiva de la representación teatral? Si bien las expresiones que se consideran posdramáticas son por demás heterogéneas, podemos caracterizarlas a partir de dos aspectos generales: el carácter problemático del texto dramático y el tratamiento fragmentario de los componentes que otrora constituían las unidades aristotélicas.

Según Lehmann (2002), el Teatro Posdramático abandona la noción de texto dramático como garante de unidad, transformando al hecho teatral en un sistema de tensiones basadas en el contraste, la oposición o la complementariedad de elementos fragmentarios, ocasionando la ausencia de diálogos realistas, de acciones claramente definidas e incluso, de entidades reconocibles como personajes. Por su parte, Cornago (2005) amplía esta idea, refiriendo que el Teatro Posdramático se define como una práctica escénica cuyo resultado 
ya no está previsto ni contenido en el texto. Esto significa que las propuestas escénicas posdramáticas recurren a textos que no poseen marcas representacionales, por lo que abunda la utilización de textos narrativos, poéticos e incluso a enunciados no literarios, como pueden ser listados o series de instrucciones.

En cuanto a la tríada lugar, acción y tiempo, el Teatro Posdramático la someterá a una descomposición de sus elementos tendiente a eliminar la posibilidad de que constituyan unidades. Así, mientras se abandona el espacio homogéneo del drama en favor de un espacio discontinuo, múltiple y fragmentado como lugar de la acción, ésta carece de la progresión provista por la lógica de la interacción, dado que los desempeños sincrónicos no se dirigen a un objetivo común, por lo que su simultaneidad no arriba a ningún tipo de resolución unitaria. En lo que respecta al tiempo, la evolución dramática por la que cada instante debe contener en sí el germen de su futuro (Szondi, 1994), lógica que presupone la idea de transformación, es suplantada por la puesta en ritmo. La misma consiste en la reiteración de momentos o comportamientos no significativos en si mismos, pero que, mediante su repetición constante o acelerada, resulta en una escansión determinada de la escena.

Consideramos que, si bien el tratamiento del texto y del espacio descripto hasta aquí conduce a una ostentación de la reflexividad escénica, es la reciprocidad establecida entre el tiempo y la acción, mediante la puesta en ritmo, la que lleva más lejos este movimiento. En efecto, si tal como lo afirma Patrice Pavis, el ritmo logra "hacer sentir la producción de signos, desalinear la escucha y la mirada habituales: buscar la fisura" (Pavis, 1994, p. 188), es a través de la repetición de una acción, que se espacializa el tiempo y se retarda el sentido, promoviendo una vinculación sensible o erótica del espectador con su objeto, por sobre una relación basada en la mera significación. Es por ello que la teatralidad, resultante de la colocación en ritmo de una acción, es tributaria de la puesta en relieve de su opacidad, por cuanto la repetición eleva la materialidad o la superficie por sobre el sentido.

Por todo lo antedicho, la acentuación de la dimensión reflexiva de la representación en el Teatro Posdramático implica la preponderancia de la presencia sobre la sustitución, del proceso sobre el resultado, de la manifestación sobre la significación, privilegiando el juego con la densidad de signos, la tendencia a la puesta en música, a la generación de una dramaturgia visual y a la preeminencia de la 
corporalidad. Todo esto en detrimento de la generación de un diálogo capaz de contrastar intersubjetivamente valores contrapuestos $y$, con ello, de la posibilidad de elaboración de personajes definidos psicológicamente, lo cual será de vital importancia para el desempeño actoral, como veremos más adelante.

Ahora bien, llegados a este punto es necesario destacar una cuestión central. La puesta en relieve de la dimensión reflexiva de la escena y su contrapartida, el desentendimiento por la transitividad del enunciado o por la construcción de la trama, no deben conducirnos al error de considerar al Teatro Posdramático como una manifestación autónoma de la materia sin un sentido, ni una subjetividad que le dé origen. De hecho, la colocación en primer plano de la opacidad del enunciado no implica en absoluto, ni en el teatro ni en cualquier otra manifestación artística o discursiva, la imposibilidad de construir algún tipo de sentido. Si esto fuese así, el enunciado sería insoportable, y aun más, imperceptible, para el espectador.

Por consiguiente, el Teatro Posdramático no se trata de una proliferación de significantes o de un caos sin origen, sino, simplemente, de una práctica escénica basada en la reemergencia del Yo épico. Sólo que, a diferencia del drama, el mismo no se halla en la persona del dramaturgo, que deja sus marcas de enunciación en el texto dramático, sino en la del Director, que hace lo propio en la puesta en escena.

En efecto, las marcas de enunciación del Yo épico en el Teatro Posdramático se hacen evidentes en el montaje, en la disposición de fragmentos heterogéneos en sucesión y/o yuxtaposición, tarea asumida por el director, rol que se fortalece en este tipo de teatro. No en vano la mayor parte de los ejemplos de Teatro Posdramático analizados por Lehmann y otros teóricos corresponden a la obra de directores.

En este sentido, el Director "posdramático" es quien dispone el material, en tanto la disposición es ya una forma de composición del enunciado, aunque sólo se limite a explicitar cuándo comienza y cuándo termina el mismo. La mayor proporción o medida en la que el espectador debe completar el enunciado, comprendiendo o construyendo el sentido allí donde supuestamente no lo hay, no implica la ausencia de composición en el Teatro Posdramático. La disposición del enunciado escénico posdramático requerirá de una atención más abierta y fragmentaria por parte del público, pero no debe confundirse la ausencia de trama o de sentido unificado, ni aun 
la de autor, con el abandono de una escena teológica, en los términos propuestos por Derrida (1967).

De modo que, si tal como lo manifiesta Cornago (2005), el Teatro Posdramático no es una corriente dramatúrgica sino una práctica teatral, concluiremos provisionalmente en que dicha práctica es eminentemente directorial. Por consiguiente, consideramos que el Teatro Posdramático no es ni más ni menos que una Poética de Dirección, autonomizada respecto de la dramaturgia, y que se constituye a partir de la disposición de elementos heterogéneos en escena (entre los que se incluye el texto, cuando lo hay), seleccionados y montados por el responsable de la puesta. Esto tendrá implicancias definitorias para el desarrollo de la Actuación en el Teatro Posdramático, tal como analizaremos a continuación.

\section{La Actuación en el Teatro Posdramático}

El reconocimiento de la Actuación como obra de arte o creación del sujeto actor, ha sido y es un problema no resuelto (y pocas veces planteado) en el arte y mas aun, en la teoría teatral.

Tal como hemos desarrollado anteriormente, la dimensión transitiva de la representación teatral ha tenido una notable preponderancia durante buena parte de la historia del teatro occidental. Sin embargo, y debido al carácter de la acción como acontecimiento, la Actuación siempre ha perturbado dicha transitividad hacia el referente. En efecto, la particularidad de la Actuación proviene de su cualidad de acción realizada, y por lo tanto, inmanente (por cuanto es inherente a sí misma, sin referencia a algo externo) e indeterminada (por cuanto se da en el aquí y ahora de su ejecución), lo cual plantea siempre una dimensión de riesgo y un cuestionamiento a la totalidad del hecho escénico entendido como una composición previa y controlable. El sujeto, en tanto ser corpóreo (Merleau Ponty, 1975), es el elemento perturbador por antonomasia de la transitividad del enunciado escénico, debido a que su desempeño en el aquí y ahora del hecho teatral introduce elementos ajenos o diversos respecto del referente (tal como vimos, constituido por la trama), enfatizando así el carácter reflexivo de la representación.

Por consiguiente, consideramos que, tanto las nociones de representación (limitando el concepto a la transitividad) y de interpretación de un personaje, que han caracterizado a la tarea del actor en el enfoque tradicional, así como la prolongada condena moral a la 
Actuación, constituyen intentos de reducir la reflexividad que reviste la acción del actor en escena y su consiguiente carácter disruptivo de la transparencia hacia el referente. La solución ha consistido en postular a la acción actoral como la sustitución de la acción del personaje, en tanto construcción discursiva creada por el dramaturgo. En este esquema, el personaje se constituye en la instancia mediadora entre la trama y el actor. El sentido representado, heterogéneo y extemporáneo a la Actuación, es erigido así como la justificación última de la acción del actor. Como resultado, los aspectos específicos de la Actuación, en tanto acontecimiento, permanecen inadvertidos.

Esto posee dos consecuencias. Por un lado, las constantes sospechas y reprimendas dirigidas a la Actuación en tanto elemento disruptivo de la representación. En este sentido, todo aquello del desempeño actoral que no sea estrictamente transparente hacia la trama, es decir, lo que constituye lo específicamente actoral, será percibido como "ruido" o desorden. Se opera entonces, lo que hemos denominado como "atribución selectiva" de la Actuación (Mauro, 2011). Mediante la misma, los aspectos transitivos de la acción actoral son asimilados a la representación del personaje (en tanto entidad emanada de la trama y, por lo tanto, creación del dramaturgo), mientras que adquieren un carácter réprobo todos los aspectos relacionados con la actividad actoral en tanto profesión y todos los elementos de la Actuación que ostentan un carácter reflexivo, los cuales son atribuidos negativamente al actor como sujeto. Esto da lugar a la segunda consecuencia, que es la no menos prolongada indeterminación técnica de la tarea actoral a lo largo de la historia del teatro occidental (del cual deriva la desconsideración teórica sobre la Actuación como fenómeno analizable).

En este orden de cosas, la llegada del Drama Moderno constituirá el punto más álgido en esta tendencia, dado que en el mismo el personaje pasa a ocupar el lugar central como fundamento de la transitividad del hecho escénico. Este será el puntapié inicial para la elaboración de metodologías actorales que reduzcan, de una vez por todas, la irrupción de la reflexividad de la Actuación a su mínima expresión o, más exactamente, que la subordinen por completo a la representación del referente. Nos referimos al naturalismo y, fundamentalmente, al denominado sistema Stanislavski, en tanto constituye una resolución técnica de la tendencia basada en la dimensión transitiva de la representación a partir de la primacía de la trama² 
Hemos anticipado que el Teatro Posdramático implica un desentendimiento por la trama que llega a veces hasta su abolición o a la desaparición de entidades reconocibles como personajes, al tiempo que propone una reivindicación de la dimensión reflexiva de la representación teatral. No obstante, esta puesta en relieve de la reflexividad, en la que la presencia física del actor es un pilar fundamental, no debe inducirnos a creer que la Actuación pasa ahora a ser percibida en sí misma como creación. A pesar de la importancia que adquiere el desempeńo actoral en las manifestaciones teatrales posdramáticas, la Actuación no logra ni autonomizarse ni obtener el status de obra de arte o creación que se le ha negado durante siglos.

$Y$ es aquí donde el fortalecimiento del rol de director y su asunción exclusiva del Yo épico en el Teatro Posdramático adquiere todas sus implicancias. De este modo, si bien el Teatro Posdramático es una práctica directorial que se apoya fuertemente en la presencia y la creación de los actores, mediante la selección y combinación de los elementos encontrados por el actor, estos hallazgos son apropiados por el director. En este sentido, consideramos que el Teatro Posdramático como práctica directorial se constituye a partir de una vampirización del director respecto de la creación de los actores. De hecho, reiteramos, las obras analizadas se adjudican como creación de los directores y no tienen carácter colectivo, permaneciendo en gran medida anónimos los actores. De este modo, también opera aquí una atribución selectiva de la tarea y de los logros del actor.

Esto nos coloca de cara al proceso creativo propio de la práctica posdramática y a la relación establecida durante el mismo entre actores y director. En primer término, debemos destacar que el Teatro Posdramático no se caracteriza por ser ni improvisado ni indetermina$\mathrm{do}^{3}$, por lo que el ensayo se constituye en una instancia fundamental para el descubrimiento y la posterior disposición del material escénico. En lo que respecta al hallazgo y elaboración de los elementos fragmentarios que luego serán dispuestos en escena, la creación y experimentación del actor ocupa un lugar preponderante, dado que muchas veces no cuenta ni con un texto ni con un personaje previo. Damos por descontado que este trabajo puede ser guiado en mayor o menos medida por la instancia directorial, pero consideramos que el Teatro Posdramático apela más enfáticamente que otras prácticas escénicas a los hallazgos de los actores como material de base para la elaboración del enunciado teatral. 
En este punto, juzgamos pertinente revisar las observaciones de Richard Schechner (2000) respecto del concepto de performance. Basándose en la noción de Austin, quien define mediante este concepto a la categoría del lenguaje que "hace" algo en lugar de describirlo o expresarlo, es decir, en lugar de "referirse" a ello, Schechner postula la existencia de una dimensión performativa presente en todo acontecimiento y no sólo en los hechos artísticos que así se autodenominan. Para analizar dicha dimensión estima que es necesario tomar a la actividad o suceso en cuestión, en su calidad de "conducta restaurada" o "conducta practicada dos veces". Con estas expresiones Schechner da cuenta de acciones que nunca son realizadas por primera vez, sino por segunda y ad infinitum, es decir, que son repetidas y nunca originales. La paradoja de la performance radica en que cada una de las repeticiones es diferente de las otras, mientras el concepto de lo performativo se basa en la repetición y la restauración. Se trata de una copia sin original. ¿Qué es entonces lo que se repite? La esencia de la performance es que el original es construido como efecto de las diversas repeticiones, por lo que los sistemas están en flujo y reversibilidad constantes, no pudiendo establecerse claramente la distinción entre un interior o profundidad (el sentido) y un exterior, que sería su apariencia o superficie.

A partir de la propuesta de Schechner, el lector reconocerá que siempre que un actor ensaya, está "construyendo" un original a partir de las repeticiones que va proponiendo. Esto es así incluso aunque exista un texto previo y un personaje a representar, dado que, si bien estos se hallan configurados a modo literario, no se hallan formulados de modo escénico, por lo que toda Actuación es, en sentido estricto, la construcción de un original inexistente previamente, que nunca es representado por vez primera, sino por segunda vez y ad infinitum. Es por ello que consideramos que siempre ensayar es crear un original a partir de la conducta restaurada (y esto es algo que saben muy bien todos los actores $)^{4}$. El mayor o menor grado de fijación en el que decanten los resultados de esta práctica (de lo que dependerá la existencia o no de un texto previo, la poética teatral a la que se adscriba, el rol jugado por la instancia directorial etc.) no indican una diferencia cualitativa en la forma de trabajo del actor en este sentido. No obstante lo cual, convengamos que en el Teatro Posdramático los logros de la Actuación como conducta restaurada a partir del proceso de ensayos es muchas veces el único material sobre el que se basa la 
práctica directorial toda, por cuanto el original textual o la trama se hallan ausentes. Sin embargo, los resultados rara vez son percibidos o explícitamente enunciados como creación de los actores, pasando a formar parte de la propuesta del director (quien además, y como ya dijimos, muchas veces no comparte la responsabilidad del enunciado escénico con autor alguno).

En lo que respecta a la perspectiva del actor, agregaremos que a estas alturas de la historia del teatro, el mismo se halla familiarizado con su invisibilización por parte de otros componentes del hecho escénico, que usufructúan de su capacidad creadora. Estado de cosas habilitado por la hegemonía de una lógica logocéntrica y por el histórico desprecio por el cuerpo en Occidente, que conlleva a un desentendimiento por las implicancias del carácter del sujeto como ser encarnado (en los términos de la propuesta de Merleau Ponty, 1975), en favor de la supremacía de un dualismo cartesiano que está aun muy lejos de declinar. En este contexto, la creación del sujeto actor nunca es del todo suya, sino del dramaturgo o del director, sujetos portadores de la palabra y del sentido, o, en los breves períodos o contextos socioculturales en los que estas instancias son cuestionadas (por ejemplo, en las creaciones colectivas o en el Teatro Popular), los actores pasan a constituir la manifestación o la expresión de una época, que pareciera atravesarlos cual si estos fueran superficies transparentes. En definitiva, el actor nunca es considerado como sujeto de un enunciado propio.

El Teatro Posdramático no sería más que un extremo de esta tendencia, por cuanto el cuerpo del actor es, en varias propuestas, tomado como objeto. En este sentido, Lehmann refiere que el Teatro Posdramático es "post-antropocéntrico" (2002, p. 127) porque en el mismo, la jerarquía entre hombre y cosa desaparece, siendo la forma humana integrada como un elemento más en el espacio.

Por otra parte, estas y otras características específicas de la utilización de la Actuación en las propuestas posdramáticas, generan desafíos técnicos y metodológicos para los actores, quienes muchas veces deben apelar a soluciones personales para hacerles frente o a la formación en otras disciplinas artísticas, como la danza, la acrobacia y/o el canto.

Entre estos desafíos podemos mencionar, en primer término, a aquellos que derivan de las diferencias más claramente visibles entre las propuestas posdramáticas y la Actuación dramática. Nos referimos 
a lo que Lehmann caracteriza como una negación de la concepción clásica de un sujeto que basa la corporalidad de sus acciones en sus intenciones mentales. Esto conlleva directamente a la vacuidad o deconstrucción del diálogo entre personajes, que se transforma en mera conversación trivial, no traduciéndose en acción ni definiendo al sujeto que profiere la palabra. Por otra parte, la Actuación se ve privada de la interacción entre personajes como principio organizador, careciendo de la progresión generada por la réplica. Esto no sólo se produce por la ausencia o vacuidad de los diálogos, sino también por la yuxtaposición de acciones sincrónicas sin relación entre sí.

De este modo, se privilegia la yuxtaposición de actores en un mismo espacio sin necesariamente interactuar. Esto tiene dos consecuencias. Por un lado, que la tarea del actor se evidencie como una lucha por la focalización del espectador, dado que la organización del espectáculo no garantiza la misma mediante las réplicas o las acciones. Por otro, se promueve el desarrollo de una gran pericia por parte de los actores para los desempeños individuales, propiciando una exacerbación de los aspectos meramente plásticos de la utilización del cuerpo (incluyendo el uso de la voz como materia expresiva) y, como contrapartida, la pérdida de la capacidad para relacionarse con otros actores en escena, lo cual se traduce muchas veces en actuaciones vacías o inexpresivas 5 .

Asimismo, la disminución o desaparición de la interrelación entre los personajes o roles jugados en escena decanta en la orientación de los actores hacia la platea, a la manera de un coro. De este modo, es recurrente el uso de la posición frontal y la mirada hacia el público, como medios para evidenciar el mecanismo de la obra en tanto relación entre actor y espectador. No obstante, se recurre a mediaciones que delimiten la separación entre actor y platea, tal como el uso de dispositivos técnicos, entre los cuáles los micrófonos son los más elegidos.

Por último, un aspecto menos evidente para el espectador o el analista, deriva del abandono de la construcción del personaje propia del Drama, en favor de la ya mencionada puesta en ritmo a partir de una paleta de movimientos o gestos reiterados por parte del actor. Así, mientras el actor dramático construye su Actuación a partir de la dependencia del concepto de circularidad, en tanto continuidad, relajación o fluidez rítmica (Bartís, 2003), el Teatro Posdramático plantea una hipercodificación de las reiteraciones, redundando en la generación de una serie rítmica discontinua o fragmentaria. 


\section{La Actuación en el Teatro Posdramático Porteño}

Nos queda por analizar, entonces, a partir de qué momento puede reconocerse la presencia de prácticas posdramáticas en el teatro porteño. Consideramos que para hacerlo, es necesario dirigir la indagación hacia el rol jugado por la Actuación durante las últimas décadas, como factor dinamizador del hecho escénico porteño en su conjunto.

Tal como lo ha señalado Osvaldo Pellettieri (2001, p. 48), el campo teatral argentino se ha caracterizado por la presencia de una constante realista. En efecto, primero como aspiración y con el avance del siglo XX como logro, el realismo en tanto garantía de la transitividad hacia el referente ha dominado la centralidad del campo. Gran parte de este objetivo tenía que ver con la concreción de una dramaturgia autóctona que transmitiera contenidos valorados por los sectores intelectuales, así como con lograr que la Actuación se subordinara a dichas textualidades, lo cual en nuestro contexto implicaba el abandono de parámetros nacionales y populares ${ }^{6}$, y la adquisición de metodologías de trabajo europeas. Esta larga búsqueda culminará con la introducción del "sistema" Stanislavski en el año 1959 y el posterior desarrollo de una corriente dramatúrgica denominada "realismo reflexivo" (Pellettieri, 2002). El final de la década de 1960 y el inicio de la siguiente, signados por la radicalización política, convirtieron en obligación el compromiso ideológico, profundizando aun más la opción por el realismo. Esto se extenderá aun durante la última dictadura militar (1976/1983), constituyendo el ciclo Teatro Abierto el punto culminante de la utilización del teatro como modo de manifestación pública contra el gobierno de facto.

Con el advenimiento de la democracia en $1983^{7}$, y si bien el centro del campo teatral continuaría siendo ocupado por el realismo hasta el final de la década, surgirá no obstante una nueva generación de actores que reaccionarán fuertemente al mismo. Se trata del denominado under, fenómeno de reunión y proliferación espontánea de numerosas expresiones de nuevos artistas, que tuvo lugar en el campo teatral porteño a partir de los primeros años de la democracia y que finalizó a principios de la década de $1990^{8}$.

Las experiencias escénicas del under conformaron un teatro de artistas jóvenes para un público joven, lo cual amplió el fenómeno más allá del campo, apelando e incorporando a espectadores no teatrales. Fundamentalmente, esto se produjo merced a la asunción y aprovechamiento de las prácticas y conductas enunciativas y 
espectatoriales propias del mundo del rock, ámbito que ya contaba con un amplio desarrollo y una gran difusión en el campo cultural porteño desde hacía más de una década. Esto consistió en la invasión de espacios propios del rock, en la adopción de algunas de sus formas características, entre las cuales se destacan la conformación de grupos artísticos y la incorporación del horario de madrugada, produciendo la consiguiente mixtura o intercambio entre música y teatro, y fundamentalmente, provocando el establecimiento de una relación incierta y cuerpo a cuerpo entre el actor y un espectador no teatral, la cual adquirió una dimensión de peligro o riesgo inédita en el teatro porteño. En efecto, estas nuevas prácticas escénicas se basaban principalmente en el vínculo con el espectador como aspecto prioritario del hecho teatral, caracterizado así por su inmanencia e indeterminación?.

Por un lado, el under se basó en la afirmación del cuerpo del actor en la escena. La corporalidad pasó a constituir la condición de posibilidad de la exhibición, e incluso, del ofrecimiento del actor al público. Por ello, el actor comenzó a invadir el espacio del espectador, moviéndose entre el público, al tiempo que privilegió las manifestaciones físicas y sexuales revulsivas y transgresoras. El under se caracterizó entonces por el enfrentamiento cuerpo a cuerpo con el público, la indeterminación de las propuestas artísticas, la imposición del hecho teatral al espectador y la provocación a través de una corporalidad descentrada.

Por otra parte, recurrió a la exaltación de los géneros considerados periféricos aun dentro del teatro popular. Se trata fundamentalmente de la incorporación de elementos del teatro varieté o de variedades, del café concert, del circo, y de una revalorización del recital de poesía y de los discursos televisivo y cinematográfico, privilegiando la estructura fragmentaria del sketch, la producción de un efecto rápido y directo en el público, y las manifestaciones ligadas al humor (con una fuerte apelación a lo escatológico, lo sexual y lo bajo) y al melodrama.

Las expresiones del under, en las que la Actuación adquirió el lugar central, se basaban estrictamente en la exaltación de los aspectos reflexivos de la representación, exacerbando su dimensión lúdica como modo de prescindencia intencional de cualquier propósito ideológico programático, tornando vacua o trivializando la transitividad del enunciado. Así, el rechazo por cualquier discurso 
ideológico-político articulado constituyó una forma de diferenciación con aquello que había caracterizado al campo teatral durante el período inmediatamente anterior.

En este sentido, el under prescindió de dramaturgia, apelando a la creación colectiva y retomando tanto las textualidades como los rasgos ideológicos, estéticos y temáticos de la poesía neobarroca del período ${ }^{10}$. Pero fundamentalmente, aquello de lo que los jóvenes artistas del under abjuraron, fue de una instancia directorial unificadora, lo que motivó que la Actuación se tornara un componente escénico autónomo.

Tanto las agrupaciones como las manifestaciones artísticas que la crítica, el público y los mismos artistas nuclearon bajo el epíteto under, fueron profundamente disímiles y eclécticas, diferenciándose por la propuesta estética y por el mayor o menor grado de indeterminación y riesgo que gradualmente fueron intensificando o abandonando. Entre los artistas que podemos citar se hallan Las Gambas al Ajillo, Los Melli, Los Macocos, La Organización Negra, El Clú del Claun, etc. No obstante, los máximos exponentes del under fueron Alejandro Urdapilleta, Humberto Tortonese y, fundamentalmente, Salvador Walter Batato Barea ${ }^{11}$.

Dadas sus características intrínsecas, el under constituyó un fenómeno efímero que para 1992 ya se hallaba clausurado. Por un lado, y como hecho simbólico, el 13 de diciembre de 1991 muere Batato. Pero además, confluyen a inicios de la década de 1990, varios hechos que paulatinamente disolverán el fenómeno dentro del campo teatral: los propios artistas adoptaron formas de producción tradicionales, ingresando al teatro comercial o a la televisión, u optaron por el retiro, varios grupos se disolvieron y algunos espacios emblemáticos cerraron sus puertas ${ }^{12}$ o cambiaron sus pautas artísticas.

Por otra parte, si bien las manifestaciones del under fueron rápidamente legitimadas en el campo cultural durante los años 1980 (aspecto que se halla estrechamente relacionado con la política cultural del gobierno alfosinista, que sostenía una fuerte apelación a la juventud), ya a principios de la década siguiente el panorama sociopolítico cambió ostensiblemente. La transgresión se transformó en moda, siendo adoptada como tópico por los medios de comunicación y la cultura dominante, vaciándolo de su componente experimental, cristalizándolo como fundamento de nuevos y promocionados modos de consumo, y convirtiéndose así en funcional a la ideología 
neoliberal ${ }^{13}$. Ante semejante despliegue, las manifestaciones teatrales del under quedaron desactivadas.

También motivos intrínsecos a la propia estética del under llevaron a su agotamiento. Después de la novedad y transgresión inicial, el fenómeno no pudo tomar un rumbo que redoblara la apuesta y rápidamente, las propuestas se transformaron en la búsqueda del efecto inmediato. Así, la crítica comenzó a denunciar la reiteración y a propugnar por un cambio de rumbo. Por un lado, reclamando una política cultural definida, lo cual llegaría algunos años después con los subsidios gubernamentales, que contribuirían a la constitución del circuito teatral alternativo u off. Por otra parte, exigiendo el regreso a parámetros artísticos anteriores, fundamentalmente bregando por la aparición de una nueva generación de dramaturgos, lo que también sucedería en la década de 1990.

En efecto, en dicha década surgió una nueva dramaturgia, propugnada por jóvenes teatristas (denominación que contempla no sólo el rol de creador del texto dramático, sino también el de director e incluso actor). Acordamos con Ricardo Bartís (2003) cuando afirma que estos dramaturgos tomaron las características que la Actuación había adquirido en el under, para incorporarlas al texto dramático, propugnando la idea de que se podía hacer teatro de vanguardia desde una literatura de vanguardia, lo cual no le dejaba resquicio al actor.

La Actuación quedó así subordinada a un programa de puesta en escena que fue reivindicado por y adjudicado a estos jóvenes dramaturgos-directores, quienes rápidamente fueron legitimados dentro del campo teatral, convirtiéndose en figuras ${ }^{14}$. Fuertemente influenciados por el teatro de los países centrales, hacia cuyas manifestaciones experimentales dirigían mayormente su atención (tendencia se retroalimentó por su vertiginosa inserción en la dinámica de los festivales internacionales) los teatristas surgidos en los 1990 abjuraron del realismo, inclinándose por una ética y estética de características posdramáticas. En efecto, el desempeño de estos teatristas se basó en la puesta en escena de textos dramáticos propios que ya poseían marcas de indeterminación que promovían una práctica diretorial posdramátcia, asumiendo el total control del hecho escénico ${ }^{15}$.

De este modo, los logros conseguidos por los actores del under pasaron a formar parte de las herramientas y procedimientos disponibles para los teatristas, razón por la cual consideramos que el fenómeno de disolvió en el campo teatral (e incluso cultural) porteño. 
Por consiguiente, consideramos que dado que el under prescindió del concepto de director, sólo puede hablarse de teatro posdramático en la Argentina cuando sus hallazgos estéticos pasaron a ser herramientas disponibles para una práctica directorial, lo cual sucedió recién en la década de 1990.

\section{Conclusiones}

En el presente artículo hemos caracterizado al Teatro Posdramático como práctica directorial, en tanto se basa en una autonomización de la responsabilidad del director sobre la totalidad del enunciado escénico. Esta preponderancia se refuerza a través de la ostentación de marcas de enunciación, lo cual implica una reaparición del Yo épico, borrado durante la hegemonía del drama moderno.

Posteriormente, hemos analizado los vínculos establecidos entre la práctica directorial posdramática y la Actuación. Hemos afirmado que la dirección basa su propuesta estética en el aprovechamiento de los logros de los actores, creación que se emprende a partir de un proceso de ensayos que prioriza el carácter performático de la Actuación, en tanto conducta restaurada.

Por último, analizamos el caso porteño y establecimos que recién en la década de 1990, y con el surgimiento de una poética directorial que aprovechó las experiencias actorales del denominado fenómeno under, centradas en la opacidad del enunciado y en la no necesidad de un referente externo, puede hablarse de Teatro Posdramático en la Argentina. Consideramos que esto se hace en detrimento de la Actuación, dado que estos rasgos dejan de ser un fin en sí mismo, para pasar a estar nuevamente al servicio de la dramaturgia y la dirección, perdiendo así gran parte de su dimensión acontecimental. En este sentido, el eclecticismo de metodologías actorales que se observa en la actualidad, resulta funcional para una práctica directorial posdramática.

Como conclusión final de las reflexiones expuestas en este trabajo, consideramos que la noción de Teatro Posdramático se ha revelado pertinente para esclarecer este aspecto específico de la Actuación y del teatro porteño durante las últimas dos décadas, y no así, para manifestaciones anteriores. 


\section{Notas}

${ }^{1}$ Utilizaremos la noción de campo teatral formulada por Osvaldo Pellettieri (2002) a partir del concepto de campo cultural de Pierre Bordieu (1967). El campo teatral se define como un espacio social relativamente autónomo conformado por agentes (autores, actores, directores, productores, instituciones etc.) que actúan como líneas de fuerza que se oponen y se agregan, en una lucha por apropiarse del capital cultural y obtener la legitimidad en el interior del mismo, otorgada por instancias de selección, consagración y difusión. Cada agente posee una propiedad particular y un peso funcional derivados de su posición en el campo, que puede ser central o marginal.

2 Para un análisis en mayor profundidad, ver Mauro (2011a; 2011b; 2010).

${ }^{3}$ Esta es una de las diferencias fundamentales que ostenta el Teatro Posdramático respecto de las propuestas experimentales inmediatamente anteriores, como las del denominado Nuevo Teatro norteamericano y europeo de los años 1950 y 1960 (De Marinis, 1987), que se apoyaba fuertemente en la utilización del formato happening, que habían tomado de las artes plásticas. El caso paradigmático dentro de este movimiento es el del Living Theatre, cuya tendencia hacia la indeterminación e improvisación en los espectáculos como modo de unión entre el arte y la vida, derivó en el abandono de lo teatral y el paso a la acción política directa. En este sentido, el Teatro Posdramático que lo sucedió constituyó un repliegue a lo específicamente teatral, preservando la división estricta entre escenario y platea Para profundizar, ver Mauro (2011a).

${ }^{4}$ En este sentido, el personaje y la representación de la trama son, en cualquier tipo de teatro, un efecto y no una causa de la acción actoral. Así, la ausencia evocada por la dimensión transitiva de la representación teatral nunca es en sentido estricto sustituida, sino construida por la Actuación. Para mayor profundidad, ver Mauro (2011a; 2010).

${ }^{5} \mathrm{Al}$ respecto, el pedagogo y director argentino Raúl Serrano afirma que estas propuestas suelen ser movedizas y dinámicas, pero frías, dado que los actores se desempeñan en ellas como si se tratara de cosas para ser vistas, dado que "todo lo expresivo sucede en la dimensión plástica” (Serrano, 2004, p. 9).

${ }^{6}$ Para una caracterización de las formas de Actuación populares desarrolladas en el teatro porteńo, ver Pellettieri (2001) y Mauro (2011).

${ }^{7}$ El 10 de diciembre asume la presidencia Raúl Alfonsín, quien se mantendrá en el gobierno hasta 1989.

${ }^{8}$ Es necesario distinguir el contenido semántico original del epíteto under, del que adquiere en su aplicación a las experiencias teatrales de los años 1980. El término proviene del inglés underground, con el que se denominaron a las tendencias surgidas en la juventud norteamericana de los 1960, del cual formó parte el hippismo, el Nuevo Teatro y la música de rock (Maffi, 1975). Con el correr de la década, parte del underground norteamericano se diluyó en el Movement y luego en la lucha política directa. El rock, por otra parte, se asimiló a la industria cultural a través de su inserción en los medios masivos. Dada su falta de interés por el discurso político en términos tradicionales, el término under utilizado para la experiencia argentina no abarca el mismo sentido que el fenómeno norteamericano, 
excepto por la relación con componentes del imaginario inherente a la música de rock. En sentido estricto, el under porteño se asemejó más a lo que se conoce como La Movida española. No obstante, si existe un punto de confluencia entre todos estos movimientos, el mismo se halla en la importancia que la juventud, en tanto actor social diferenciado, adquiere en los mismos.

${ }^{9}$ Para mayor profundidad, ver Catalán (2005).

${ }^{10} \mathrm{El}$ neobarroco es un movimiento literario surgido en la isla de Cuba, cuyos lineamientos son establecidos por Severo Sarduy (1972). En la Argentina, durante la década de 1980, el concepto neobarroco se extiende a una zona menor de la literatura que interpela a las formas canónicas. Las mismas están compuestas por las obras y figuras de escritor rescatadas por Néstor Perlongher, quien acuña el término "neobarroso" para dar cuenta de la variante local del estilo enunciado por Sarduy, en la que el barroco se mezcla con el barro del Río de la Plata. Se trata de un "barroco de trinchera" o del cuerpo a tierra, que presenta una intensificación del racionalismo, la ironía, la nostalgia, el escepticismo y el psicologismo, representado principalmente por Osvaldo Lamborghini y César Aira, aunque también pueden incluirse entre los neobarrocos, a Alejandra Pizarnik y Marosa Di Giorgio (Minelli, 2006).

${ }^{11}$ La prolífica aunque breve trayectoria de Batato, así como su derrotero personal, fueron definitivos para delinear el fenómeno under. Inicialmente formado en la metodología del clown, pronto optó por manifestaciones artísticas más cercanas al universo de la performance tanto en solitario como en diversas formaciones (Los peinados Yoly, El Clú del Claun y finalmente, el famosísimo trío conformado junto con Urdapilleta y Tortonese). Batato fue ganando popularidad conforme el under se fue afianzando. No obstante, con el correr de los años, mientras otras agrupaciones optaban por la paulatina profesionalización, Batato extremó su elección por el espectáculo indeterminado y performático, hasta su muerte en 1991.

${ }^{12}$ Como es el caso de la primera sede del mítico Parakultural que fue clausurado en 1990.

${ }^{13}$ Implementada en el país por el gobierno de Carlos Sául Menem (1989/1999).

${ }^{14}$ Entre estos artistas, podemos mencionar al grupo Periférico de Objetos, formado por algunos teatristas que luego encararían obras individuales, como Daniel Veronese, Ana Alvarado y Emilio García Wehbi, y a dramaturgos-directores como Javier Daulte, Alejandro Tantanian y Rafael Spregelburd, de prolífico desempeño durante la década del 1990. Estos artistas se dedicaron además a la formación, por lo que durante la década siguiente surgió una segunda generación de teatristas con estas características.

${ }^{15}$ Para el análisis exhaustivo de una clara propuesta posdramática en el teatro porteño, Ars Higiénica, del director Ciro Zorzoli, ver Mauro (2008).

\section{Referencias}

ARISTÓTELES. Poética. Madrid: Aguilar, 1979.

BARTÍS, Ricardo. Cancha con Niebla. Buenos Aires: Atuel, 2003. 
BOURDIEU, Pierre. Campo Intelectual y Proyecto Creador. In: AAVV. Problemas del Estructuralismo. México: Siglo XXI, 1967. P. 135-182.

CATALÁN, Alejandro. El Actor como Escenario. Revista Conjuntos, La Habana, Casa de las Américas, n. 136, p. 31-42, jun. 2005.

CHARTIER, Roger. Poderes y Límites de la Representación. Marin, el discurso y la imagen. In: CHARTIER, Roger. Escribir las Prácticas. Foucault, De Certeau, Marin. Buenos Aires: Manantial, 1996. P. 73-99.

CORNAGO, Oscar. Teatro Posdramático: las resistencias de la representación. In: DUBATTI, Jorge (Org.). Escritos sobre Teatro I. Teatro y cultura viviente: poéticas, política e historicidad. Buenos Aires: Nueva Generación, 2005. P. 119-141.

DE MARINIS, Marco. El Nuevo Teatro. 1947-1970. Barcelona: Paidós, 1987.

DERRIDA, Jacques. El Teatro de la Crueldad y la Clausura de la Representación. In: DERRIDA, Jacques. La Escritura y la Diferencia. Barcelona: Antrhopos, 1967. P. 318-343.

LEHMANN, Hans-Thies. Le Théatre Postdramatique. París: L'Arche, 2002.

LYOTARD, Jean-François. La Condición Posmoderna. Madrid: Cátedra, 1987 [1979].

LYOTARD, Jean-François. El Diente y la Palma de la Mano. In: LYOTARD, Jean-François. Dispositivos Pulsionales. Madrid: Fundamentos, 1981. P. 84-102.

LYOTARD, Jean-François. Tomar Partido por lo Figural. In: LYOTARD, Jean-François, Discurso y Figura. Barcelona: G. Gili, 1970. P. 63-95.

MAFFI, Mario. La Cultura Underground. Barcelona: Anagrama, 1975.

MAURO, Karina. La Técnica de Actuación en Buenos Aires. Elementos para un Modelo de Análisis de la Actuación Teatral a partir del caso porteńo. 2011. 626 f. Tesis (Doctorado en Historia y Teoria de las Artes) - Facultad de Filosofía y Letras, Universidad de Buenos Aires, 2011.

MAURO, Karina. Alcances y Límites de una Perspectiva Canónica: la Actuación entre las nociones de "representación" y de "interpretación". In: LARIOS RUIZ, Shaday. Escenarios Post-catástrofe. México: Artezblai, 2011. P. 51-92.

MAURO, Karina. Problemas y Limitaciones de la Acción Actoral entendida como representación. Afuera - Revista de Estudios Culturales, Buenos Aires, a. V, n. IX, p. 1-22, nov. 2010. Disponible en: <http://www.revistaafuera.com.ar/>.

MAURO, Karina. Teatro Posdramático y Técnicas de Actuación en la Argentina. El caso Ars Higiénica. Revista Espacios de Crítica y Producción, Buenos Aires, Universidad de Buenos Aires/Facultad de Filosofía y Letras, n. 39, p. 27-32, nov. 2008.

MERLEAU PONTY, Maurice. Fenomenología de la Percepción. Barcelona: Península, 1975.

MINELLI, María Alejandra. Algunas formas menores en la cultura argentina de fines del siglo XX. Astrolabio, Córdoba, Universidad Nacional de Córdoba/Centro de Estudios Avanzados, n. 2, p. 1-8, 2006. Disponible en: <http://www.astrolabio.unc.edu.ar/articulos/ nuevosfrutos/articulos/minelli.php/>. Acceso en: 25 sep. 2009. 
PAVIS, Patrice. El Teatro y su Recepción. Semiología, cruce de culturas y postmodernismo. La Habana: UNEAC/Casa de las Américas, 1994.

PELLETTIERI, Osvaldo. Introducción. In: PELLETTIERI, Osvaldo (Org.). Historia del Teatro Argentino en Buenos Aires - Volumen II. Buenos Aires: Galerna, 2002. P. 13-37.

PELLETTIERI, Osvaldo. En Torno al Actor Nacional: el circo, el cómico italiano y el naturalismo. In: PELLETTIERI, Osvaldo. De Totó a Sandrini. Del cómico italiano al 'actor nacional' argentino. Buenos Aires: Galerna, 2001. P. 7-24.

RANCIÈRE, Jacques. El Espectador Emancipado. Buenos Aires: Manantial, 2010.

SARDUY, Severo. Ensayos Generales sobre el Barroco. Buenos Aires: FCE, 1987 [1972].

SCHECHNER, Richard. Performance. Buenos Aires: Universidad de Buenos Aires, 2000.

SERRANO, Raúl. Nuevas Tesis sobre Stanislavski. Buenos Aires: Atuel, 2004.

SZONDI, Peter. Teoría del Drama Moderno (1880-1950). Barcelona: Destino, 1994 [1956].

Karina Mauro es doctora en Historia y Teoría de las Artes por la Universidad de Buenos Aires (UBA). Investigadora Asistente del Consejo Nacional de Investigaciones Científicas y Técnicas (CONICET). Se especializa en Teoría e Historia de la Actuación en Teatro y Cine. Es Profesora Adjunta de la asignatura Historia Sociocultural del Arte I y II (IUNA), y Docente Regular de la asignatura Psicología del Arte (Facultad de Filosofía y Letras, UBA). Investigadora del GETEA (Facultad de Filosofía y Letras, UBA). Actriz y cantante.

E-mail: karinamauro@hotmail.com

Recibido el 23 de abril de 2013 Aceptado para publicación el 30 de junio de 2013 